\title{
PHENOLIC COMPOUNDS FROM ROOTS OF Lupinus polyphyllus
}

\author{
V. V. Boinik, Kh. P. Akritidu, * and O. V. Demeshko
}

We reported earlier on the isolation from Lupinus polyphyllus Lindl. roots of 20 organic acids, among which 10 were carboxylic; 2, phenolic; and 8 , fatty acids [1].

The goal of the present work was to study phenolic compounds from L. polyphyllus roots.

We studied roots collected during fruiting in September 2014 in Kharkov Region of Kharkov Oblast.

Total phenolic compounds were separated into individual components using HPLC on an Agilent Technologies 12003 D LC System chromatograph (USA) equipped with G1325C diode-matrix and G1362A refractometric detectors.

The investigation used reversed-phase (RP) chromatography over a Supelco Discovery $\mathrm{C}_{18}$ chromatography column $(250 \times 4.6 \mathrm{~mm})$ with silica gel $(5 \mu \mathrm{m})$ modified by octadecyl groups. The mobile phase was solvent $\mathrm{A}[0.1 \%$ trifluoroacetic acid (TFA), $\left.5 \% \mathrm{MeCN}, \mathrm{H}_{2} \mathrm{O}, \mathrm{pH} 2.08\right]$ and solvent $\mathrm{B}(0.1 \% \mathrm{TFA}, \mathrm{MeCN})$. The chromatography conditions were mobilephase flow rate $0.1 \mathrm{~mL} / \mathrm{min}$, eluent operating pressure $400 \mathrm{bar}(40 \mathrm{kPa})$, column thermostat temperature $25^{\circ} \mathrm{C}$, sample volume $10 \mu \mathrm{L}$, and chromatography time $40 \mathrm{~min}$. We used gradient elution. The scan time was $0.6 \mathrm{~s}$ at wavelengths 280 and $255 \mathrm{~nm}$.

Ground raw material ( $2.0 \mathrm{~g}$, accurate weight) was placed into a $100-\mathrm{mL}$ flask and extracted with refluxing doubly distilled $\mathrm{H}_{2} \mathrm{O}(50 \mathrm{~mL})$ for $30 \mathrm{~min}$ on a boiling-water bath. The obtained extract was filtered, cooled, transferred to a $100-\mathrm{mL}$ flask, and adjusted to the mark with doubly distilled $\mathrm{H}_{2} \mathrm{O}$ [2].

The quantitative contents in L. polyphyllus roots of gallic and ellagic acids, (+)-catechin, (+)-catechin gallate, (-)-epicatechin, epicatechin gallate, and epigallocatechin were analyzed by RP chromatography. Table 1 presents the results.

The phenolic composition of $L$. polyphyllus roots was studied. The quantitative contents of isolated compounds, the total of which was $1.972 \%$, were determined.

The dominant compounds with respect to quantity $(\mu \mathrm{g} / \mu \mathrm{L})$ were (-)-epicatechin, 213.05376; (+)-catechin, 208.05657; and (-)-epigallocatechin, 154.95159. This indicated that L. polyphyllus roots contained mainly condensed tanning agents.

TABLE 1. Phenolic Compounds from Roots of Lupinus polyphyllus

\begin{tabular}{l|c|c|c}
\hline \multicolumn{1}{c}{ Compound } & Retention time, min & $\mu \mathrm{g} / \mu \mathrm{L}$ & Concentration \\
\cline { 3 - 4 } & & 8.30934 & 0.020 \\
\hline Gallic acid & 7.589 & 208.05657 & 0.493 \\
$(+)$-Catechin & 15.341 & 154.95159 & 0.367 \\
$(-)$-Epigallocatechin & 16.569 & 127.52422 & 0.302 \\
Ellagic acid & 19.249 & 213.05376 & 0.505 \\
$(-)$-Epicatechin & 20.595 & 50.64361 & 0.121 \\
(+)-Catechin gallate & 29.682 & 69.14618 & 0.164 \\
(-)-Epicatechin gallate & 30.476 & 831.68527 & 1.972 \\
Total & & & \\
\hline
\end{tabular}

\section{REFERENCES}

1. $\quad$ Kh. P. Akritidu, V. V. Boinik, and O. V. Demeshko, Chem. Nat. Compd., 49, 501 (2013).

2. Sensitive Determination of Catechins in Tea by HPLC, Thermo Scientific, DIONEX Corp., 2011, Appl. Note 275, 9 pp.

National Pharmaceutical University, Kharkov, Ul. Pushkinskaya, 53, fax: (8057) 71425 40, e-mail: elenaakritidou@mail.ru. Translated from Khimiya Prirodnykh Soedinenii, No. 2, March-April, 2015, p. 307. Original article submitted October 3, 2014. 